\title{
UNA MIRADA DESDE LA HISTORIA ACERCA DEL ROL DE LOS MEDIOS EN LA CONSTRUC- CIÓN DE IDENTIDAD EN UNA PROVINCIA AR- GENTINA DE FRONTERA
}

\author{
CARLOS ALBERTO GARCÍA DA ROSA \\ Universidad Nacional de Misiones, \\ Posadas, Misiones, Argentina \\ e - mail: carlosagarciadarosa@gmail.com \\ NORMA G. ALVAREZ \\ Universidad Nacional de Misiones, \\ Posadas, Misiones, Argentina \\ e-mail: norma_alvarez@yahoo.es
}




\section{UMA VISÃO HISTÓRICA SOBRE O PAPEL DA MÍDIA NA CONSTRU-}

ÇÃO DA IDENTIDADE EM UMA PROVÍNCIA FRONTEIRIÇA ARGENTINA

Resumo: A instalação de estações de rádio e televisão no interior da Argentina é parte dos projetos políticos em diferentes contextos e momentos pensados para o país a partir de certas perspectivas. Por um lado, podemos citar a necessidade de construir uma identidade nacional baseada no reconhecimento da diversidade e da própria sociedade multicultural diferença e em segundo lugar, o uso desses meios de comunicação como uma ferramenta para proteger as fronteiras políticas nas províncias fronteiriças como Misiones. As regras estabelecidas para regular o seu funcionamento, na maioria dos casos, não compareceu as próprias particularidades de cada região

Palavras-chave : Legislação ; meios de fronteira ; construção da identidade.

UNA MIRADA DESDE LA HISTORIA ACERCA DEL ROL DE LOS MEDIOS EN LA CONSTRUCCIÓN DE IDENTIDAD EN UNA PROVINCIA ARGENTINA DE FRONTERA

Resumen: La instalación de emisoras de radio y televisión en el interior de la Argentina se inscribe dentro de proyectos políticos que en contextos y momentos diferentes pensaron al país desde determinadas perspectivas. Por un lado, podemos mencionar, la necesidad de construir una identidad nacional a partir del reconocimiento de la diversidad y diferencia propia de una sociedad multicultural; y por otro, el uso de estos medios como herramienta para el resguardo de los límites políticos en provincias fronterizas como la de Misiones. Las normas que dictaron para regular su funcionamiento, en la mayoría de los casos, no atendieron las particularidades propias de cada región

Palabras claves: Legislación; frontera, medios de comunicación; construcción de identidad.

\section{A HISTORICAL VIEW ABOUT THE ROLE OF MEDIA IN THE CONS- TRUCTION OF IDENTITY IN A BORDER PROVINCE ARGENTINA}

Abstract: Installation of radio and television stations in the interior of Ar-
gentina is part of political projects in different contexts and at different ti-
mes thought the country from certain perspectives. On one hand, we can
mention the need to build a national identity based on the recognition of
diversity and difference itself a multicultural society, and secondly, the use
of these media as a tool for safeguarding political boundaries in border pro- 
vinces Missions like. The rules enacted to regulate its operation, in most cases, did not attend the particularities of each region. The aim of this paper is to present a body of information to recognize communication policies, both national and provincial, which were applied in the territory and realize the role that media overtook the historical development of the province

Keywords: Legislation , border, media, identity construction 


\section{INTRODUCCIÓN}

Misiones, es un territorio pequeño, fronterizo (el $91 \%$ de sus límites lo comparte con Paraguay y Brasil) con una composición social multicultural, multiétnica y plurilingüistica que se construyó a partir del encuentro de los primeros españoles con los naturales de la región y que se enriqueció a partir de 1897 con la llegadas de oleadas de inmigrantes de todo el mundo en un contexto en donde ya estaban como matrices culturales muy fuertes la brasileña y paraguaya.

Desde su nacimiento en la región, los medios de comunicación fueron llamados a ser la herramienta que permitiera -en distintos tiempos históricos - construir- civilidad (1872), autonomía política y, paralelamente, una identidad propia que los diferenciara y a la vez incluyera dentro de los procesos que se dieron para constituir y fortalecer la nacionalidad.

En un primer momento, la prensa gráfica jugó un rol protagónico a la hora de construir y sostener una historia que uniera a este Territorio con la Nación Argentina. El diario "instala / contribuye con sus producciones a la construcción de argentinidad; pero también, a la formación de un ciudadano al que buscará identificar con lo misionero y lo argentino" (Garcia Da Rosa - Alvarez, 2012: 52).

El objetivo de este trabajo, es presentar un corpus de información que permita reconocer las políticas comunicacionales, tanto nacionales como provinciales, que se aplicaron en el territorio y que den cuenta del rol que les cupo a los medios en el desarrollo histórico de la provincia

\section{LAS PRIMERAS REGLAMENTACIONES}

A partir del 19 de agosto de 1927, se sumará la radio. Julio Teodoro Cormillot instaló la primera emisora en Misiones con el nombre de Mix, que más tarde, se denominará Bouquet.

Las medidas que se comenzaron a tomar para regular la radiofonía en la Argentina impactaron en su funcionamiento y existencia.

Por decreto del 10 de abril de 1929, se le condicionará, entre otras cosas, la emisión de propaganda política y religiosa durante las transmisiones. (Ulanovsky, 1977: 50). Le seguirá la decisión de cambiar la denominación compuesto por tres letras que se usaba hasta entonces (LOR) por una sigla conformada por dos letras y un número (LR2), a la que se agregará bajo el gobierno de Agustín P. Justo la obligatoriedad de utilización de la palabra 
Radio -entre la sigla y la marca comercial (LR2 Radio). (García Da Rosa, 2002)

En 1934, apareció el Folleto de Instrucciones sobre Radiotelefonía. Imponía nuevas condiciones para la emisión de publicidad y ejercicio del periodismo. Esta emisora no pudo cumplir, por lo que su dueño decidió trasladarla en 1935 a la localidad paraguaya de Encarnación (Paraguay), donde se le otorgó la licencia con el indicativo ZP3 y ZPA3, en la frecuencia de 1250 kilociclos.

La crónica del periodismo gráfico de la época destaca el contenido de su programación que estaba relacionado con la educación, la cultura y la lucha que por esos años emprendían los misioneros para conseguir su autonomía del Poder Central.

\section{CONSTRUYENDO IDENTIDAD}

En los años '40, la radio está en su pleno apogeo. Es el tiempo de la grandes cadenas: Splendit, El Mundo, Belgrano las que construyen nuevos mercados para sus producciones y comienzan a instalar filiales en todo el país.

Radio Belgrano, fue una de las pioneras en la región y no precisamente en esta parte de la Argentina. El 4 de diciembre de 1941 y con la firma del presidente paraguayo, Higinio Morínigo, se le autorizó “la instalación y explotación de una estación radiofónica broadcasting, por el término de 15 años" en Encarnación. Esta emisora, el 2 de junio de 1953, sería transferida con todos sus derechos y obligaciones a la Compañía Paraguaya de Radiodifusión, cuyo presidente era Carlos Madelaire, un santafesino que desde muy niño vivió en Paraguay; en donde, previo a su incursión en la radiofonía, fue editor de varios diarios, todos ellos, clausurados posteriormente por el ex dictador Alfredo Stroessner

Un año más tarde, en Posadas, el 26 de junio de 1942 comenzará a salir al aire en forma regular LT4 Radio Misiones, como integrante de la Red Argentina de Emisoras Splendid ${ }^{26}$.

26 LT 4, brindaba esta posibilidad de visibilidad para que el país pudiera conocer "las expresiones reales de las inquietudes excelentes de hacernos conocer y no debemos desperdiciarlas" (Palabras del gobernador del interino del Territorio, Roberto Peralta, en el acto inaugural de LT 4 y publicadas por el diario La Tarde, en su edición del 27 de julio de 1942). 
nación moderna, que entendía estaba constituida por ciudadanos modelados en "el orden, la disciplina y en los valores espirituales y morales de la nueva argentinidad".

Ahora bien, como sostiene Gorosito Kramer "la confrontación con la Otredad, más allá de los límites de la comunidad, étnica o nacional, no implica necesariamente la supresión de las diferencias en el interior de esos mismos espacios" (Bayardo y Lacarrieu, 1998:109).

\section{CONSTRUYENDO NACIONALIDAD}

En ese interín, en Diciembre de 1953, Misiones se convirtió en Provincia. Dos años más tarde, la Revolución Libertadora (septiembre 1955) terminará con el gobierno de Juan Domingo Perón (1946-1955 ${ }^{29}$ ) y sancionará, el 25 de noviembre de 1957, la Ley 15.460/57 de radiodifusión, que impedía la formación de cadenas y procedió a la descentralización de las mismas.

El objetivo, impedir el control oligopolio de los medios como había ocurrido durante el gobierno peronista; pero más que nada, lo que se quería era evitar que el peronismo tuviera participación en la propiedad de estas emisoras.

Es así que el servicio de radiodifusión fue declarado de interés público, y se llamó a licitación para la privatización de las radios comerciales que se hallaban en manos del Estado. Se estipuló que la adjudicación de licencias que se otorgarían por 15 años, solo se podía conceder a ciudadanos argentinos, que como máximo podían aspirar a ser dueños de una estación de radio y un canal de televisión.

LT 4 Misiones, está entre estas emisoras a privatizarse y a cuya explotación accederá Madelaire en 1958 (ex director de ZP5 Radio Encarnación), en licitación pública "entre más de cien solicitantes de toda la República" (Anuario Diario Provincia, 1964: 63). Hasta ese momento, en Misiones solo existía como medio de comunicación, esta radio, que tomará el nombre de fantasía "Argentina y Libre", y un diario de tirada provincial.

La decisión que tomó la dictadura militar impactó no solo en el modo de

29 En Misiones, luego del golpe militar y a raíz de la derogación de la Constitución Provincial -que se había sancionado en 1953-, los ciudadanos de la provincia recién en marzo de 1960 participaron nuevamente en elecciones para constituir un gobierno democrático. En esa oportunidad, el triunfo le correspondió a la Unión Cívica Radical Intransigente que llevaba como candidato a gobernador a César Napoléon Ayrault quien asumió en mayo de 1960. 
Más allá de ser una oportunidad de visibilización ${ }^{27}$, lo comercial se impone como la decisión del poder político de tener su control (Williams, 1977:15), fundamentalmente, durante los regímenes militares en que se encontró una posibilidad de "propalar contenidos ideológicos funcionales a sus emprendimientos políticos” (Matellana, 2006:164).

\section{LA HOMOGENIZACIÓN}

En 1946 aparecerá el Manuel de Instrucciones para las Estaciones de Radiodifusión, un instrumento que volverá “todavía más férreo el control, de aumentar las instancias de fiscalización y hacer más amplia y efectiva la censura" (Ulanovsky, 1977:154).

El impacto que tendrá en la región será importante, porque se impone como una guía o preceptiva general para la orientación cultural, ética y estética de los programas. Se pretendió hegemonizar la diversidad cultural existente en sociedades como la de Misiones, exigiendo la inclusión de obras en las que se debía desarrollar argumentos de ambiente argentino o que guarde vinculación con la historia o la tradición argentina (Art. 15).

Pero además, por ejemplo, ningún orador y locutor podía hacer uso del micrófono si no dominaba el idioma nacional (Art. 26 inciso c). Misiones, contaba con una riqueza idiomática muy diversa puesto que los inmigrantes ${ }^{28}$, al no haber una matriz cultural nacional lo suficientemente significativa (Bartolomé, 2000: 17 a 19) reprodujeron en la colonia el sistema que trajeron de Europa, manteniendo su cultura, idioma y tradición, en un lugar donde se hablaba fundamentalmente la lengua de los naturales: el guaraní y el portugués. Es decir, para hablar y estar en la radio, ahora hay limitaciones. No toda la diversidad estará reflejada y la localidad permanentemente deberá negociar -no sin tensión- con el medio para ser visibles en los espacios creados por el medio.

Por otra parte, en los 307 artículos del Manual, aparece con claridad que no se está permitido disentir con el proyecto que el Estado tenía para una

27 Es el momento en que "el pueblo misionero comenzó a sentirse parte de la Nación, a identificarse con ella, compartiendo los mismos problemas y festejando los mismos logros, a través de las actividades políticas, sociales y culturales de la radio" (Cordero, 2002: 67)

28 Hacia fines de la década de 1940, Misiones está ya habitada por familias que emigraron de Paraguay, Brasil, Alemania, Rusia, Ucrania, Austria, Finlandia, Noruega, Polonia, Italia, Dinamarca, Suecia, Suiza, El Líbano, Francia, Inglaterra, España y Siria. 
hacer radio, sino que abrió un camino para el reconocimiento de un público diverso y heterogéneo. El concepto era que "una radioemisora no tiene ni puede tener propietario exclusivo, es siempre de los oyentes" (Fragmento del discurso de Carlos Madelaire al inaugurar los estudios de la calle Bolívar).

Es decir, que entre 1958 y 1979, la comunidad misionera, y en particular, la posadeña, construyó con la radio - que no transmitía las 24 horas- un espacio de visibilización en donde y desde donde planteó su diversidad y diferencia, en el marco de una normativa que obligaba a las radios a seguir un modelo político cultural hegemónico planteado desde el Estado Nación.

Si bien la radio siguió siendo constructora de nacionalidad e identidad nacional [“... Todo puede separarnos menos el país. Todo puede llevarnos a la vorágine de los desencuentros, menos la identidad sustancial en lo nacional... Porque -por encima del interés individual o de círculos- está como decía Avellaneda, el interés del país..."30 (Madelaire, 2007: 146), dio lugar para que se manifiesten las identidades locales propias de una sociedad multicultural como la de Misiones.

A principios de los años '70, esta radio mudará de propiedad, pasará a identificarse como "Radio Misiones" y dejará de ser popular para encuadrar su funcionamiento dentro de los marcos que ponía la normativa para la radiodifusión en ese momento

\section{SE PIENSA EN MEDIOS PÚBLICOS}

Las ideas desarrollistas que corrían por Latinoamérica se harán sentir muy fuerte con Arturo Frondizi (1/5/1958 - 29/3/1962) en la Argentina, y con César Napoleón Ayrault (1/5/60 - 24/4/62) en Misiones.

Con la firma del Presidente, por decreto 6679 del 9 de junio de 1960, publicado en el boletín oficial en la página 487 , se facultó a la Secretaría de Estado de Comunicaciones a realizar concursos para la instalación de estaciones de televisión en el interior del país, en la que se incluyó a la capital de la provincia: Posadas.

La respuesta local a esta decisión, fue inmediata. El 14 de septiembre de 1961, se sancionó la Ley Nº 111 por el cual se creó la “Emisora de Radio y Televisión de la Provincia de Misiones". Entre sus funciones, figuraba la de "gestionar ante las autoridades nacionales el otorgamiento de las frecuencias de 
radio y televisión". Algo que no se concretará de manera inmediata, por los sucesivos golpes de estado e intervenciones federales que no permitieron mantener una situación institucional estable que garantizara la aplicación de una política en el tiempo ${ }^{31}$.

Pero generó, la posibilidad de la instalación de nuevas emisoras, como LT 13 Radio Oberá en la localidad de Oberá, a 80 km de Posadas, que salió al aire un 15 de diciembre de 1963. Con su slogan: "abriendo picadas en el éter misionero", fue la primera radio del interior de la provincia. Un año después, el 19 de Junio de 1964, salió al aire en forma definitiva LT17 Radio Provincia de Misiones, una de las tres radios del estado misionero. $Y$, meses más tarde, un 11 de diciembre de 1964, salió al aire Radio Eldorado, la que fue concebida por la población del Alto Paraná "para llenar el vacío de comunicación", en una zona donde hasta ese entonces solo se sintonizaban "emisoras del Paraguay y el Brasil, que por razones de orden geográfico, eran las que mejores llegaban a sus receptores" (Garcia Da Rosa 2004).

\section{EL CASO RADIO PROVINCIA}

En 1963, con el Dr. Arturo Illia, la Argentina recuperó para síla democracia y en Misiones, por el voto del pueblo, Mario Losada(12/10/1963-28/06/1966), fue electo gobernador. Durante su gestión se puso en valor el proyecto del gobierno provincial de contar con una emisora de radio y de televisión.

No está más el ente "Emisora de Radio y Televisión de la Provincia de Misiones", pero el espíritu de la Ley $\mathrm{N}^{\circ} 111$ se mantiene. Una de sus consecuencias, es el nacimiento de LT 17 Radio Provincia, con el objetivo de "ser un instrumento al servicio de la formación del hombre misionero en un contexto local, nacional y regional".

El 7 de octubre de 1964, la Cámara de Diputados de la Provincia le dio el encuadre legal al sancionar la Ley $N^{\circ} 227$ que establecía en su Artículo $4^{\circ}$, que para la nueva radio el régimen de su organización, funcionamiento y competencia se debía ajustar a normas "que conduzcan a una mayor elevación cultural, educacional, cívica, económica, moral y social, contribuyendo a la consolidación de los vínculos de unidad nacional y comunidad regional”.

31 Se suceden las intervenciones del Coronel. Wilde Santa Cruz (24/04/1962 25/06/1962); Escribano Emilio Gueret (25/06/1962 - 24/10/1962) y del Dr. Pablo Luzuriaga (24/10/1962 - 12/10/1963. 
Es decir, que el Estado provincial con esta norma:

* Apuntala las políticas nacionales de construcción de identidad nacional, sustentada en la presencia de lo nacional, del Estado-Nación y el reconocimiento de la Argentina como país soberano.

* Prioriza la función del medio como instancia clave para la instrucción y para la formación del ciudadano en todos sus aspectos

* Define un modelo de medio y de ciudadano, con un fin político y social muy fuerte, que nos permite sostener que se pensaba en emisoras de gestión pública. (El medio no debía perseguir la rentabilidad económica, tenía prohibido la emisión de publicidad comercial. Y, definía los criterios sobre temas y/o tratamientos de los mensajes que debían o no incluirse en la programación. Se fijaba así desde órganos del Estado lo que podía o no escuchar la audiencia)

Posteriormente, por Ley 280 del 2 de julio de 1965, se autorizó el uso de esta emisora para la difusión de proyectos, leyes, resoluciones, comunicados del gobierno de la provincia y los municipios, respecto de ordenanzas y resoluciones; y, además, permitió a los partidos políticos, 40 días antes de los comicios por un lapso de cinco minutos diarios, a hacer proselitismo político.

\section{NACE LA TV PROVINCIAL}

Con Juan Carlos Onganía (29/6/1966 - 8/6/1970), en junio de 1966 se abrió un período que se denominará "Revolución Argentina" y se extenderá hasta 1973. Durante este tiempo se dictarán normas que retomarán la decisión de instalar un canal de televisión abierto en Misiones.

En 1968, el Consejo Nacional de Radiodifusión y Televisión -por acuerdo 153, del 12 de agosto, llamó a concurso público (por el término de 240 días corridos posteriores a la fecha de publicación en el Boletín Oficial) para la adjudicación de licencias para funcionamientos y explotación de canales de televisión correspondientes a estaciones secundarias y menores, en zonas del interior del país (B.O. 16/8/68, pág. 2623). En este llamado se incluyó a Misiones: Posadas, estación menor (Canal 12).

Un año después, el 8 de septiembre de 1969, por decreto 5067 y 5068 , con la firma de Onganía, Francisco A. Imaz y Julio A. Taglia, se autorizó al Gobierno de Misiones a poner en funcionamiento una estación de televisión 
en Posadas. Se le asignó el uso del Canal 12 y la señal distintiva “LT 85". Esta norma se publicó en el Boletín oficial el 16 de ese mes.

El 18 de agosto de 1971, el gobierno de Misiones, en una nota dirigida al Ministro de Industria, Comercio y Minería de la Nación, General de División, Oscar Chescotta, solicitaba la importación del equipamiento para este canal, fundamentando la importancia de este medio de comunicación en la zona: “En cuanto ellos habría de cumplir las altas finalidades que le son propias en los campos culturales, educacionales y de información, sino que la provincia por especiales características geopolíticas (la mayor parte de su extensión limita con países extranjeros) y la gran variedad étnica de su población lo que convierte en imperiosa la necesidad de incorporar este moderno medio masivo de comunicación para apoyar los planes de argentinización, radicación y arraigo de sus habitantes, promoviendo en forma sostenida los límites internacionales y favoreciendo su desarrollo"32

De esta manera, el 18 de noviembre de 1972 se emitieron las primeras imágenes y se inauguró formalmente este medio.

Con esta misma impronta, el 20 de Abril de 1972 salió al aire en Puerto Iguazú, LR 19 Radio Nacional. Fue la primera emisora de potencia media que se instaló en la triple frontera con el objetivo de "contrarrestar la penetración” de las radios de Asunción, Curitiba, San Pablo y Foz de Iguazú, que transmitían en AM y FM con alta calidad y potencia.

Un año más tarde, el 1 de abril de 1973, en San Javier -con la misma intención de ser "una barrera contra la penetración de las radios esencialmente brasileñas"- salió al aire en baja potencia, pero transmitiendo en AM, LT 46. Nació por la decisión de 20 socios de la entonces Cooperativa Azucarera de San Javier como "un aporte patriótico" de los colonos que vivían en la frontera.

El fin es claro "construir nacionalidad y soberanía en el marco de la Doctrina de la Seguridad Nacional" y los nuevos medios que saldrán al aire lo harán en ese contexto. (García Da Rosa-Alvarez: 2012)

\section{EL IDIRATEMI}

En 1973 se recuperó la democracia y en la Argentina, Héctor Cámpora (25/5/1973 - 13/7/1973) fue electo presidente. En Misiones, asumió como

$32 \quad$ Nota N ${ }^{\circ} 665-\mathrm{V}-71$ del 16 de febrero de 1971. 
gobernador, por decisión también de los misioneros, Juan Manuel Irrazábal (25/05/1973 - 30/11/1973), quién junto con su vicegobernador y respectivas esposas fallecerán, seis meses de haber asumido, en un trágico accidente de aviación. Al día siguiente de este hecho, que enlutó a los misioneros, el $1^{\circ}$ de diciembre de ese año, asume como gobernador interino el escribano Luis Ángel Ripoll.

Destacamos este acontecimiento, porque es durante su mandato, concretamente a 28 días de hacerse cargo del Ejecutivo, que la Cámara de Diputados de la Provincia sancionó la Ley $\mathrm{N}^{\circ} 405$, norma que rescata el espíritu de la Ley Nº 111 de 1961, del proyecto del Ente "Emisora de Radio y Televisión de la Provincia de Misiones", que reaparecerá -con modificaciones- 13 años después, como "Instituto de Difusión, Radio y Televisión de Misiones" (IDIRATEMI), del cual pasa a depender el Canal 12 y LT17 Radio Provincia. En el Decreto $N^{\circ} 355$, del 20 de febrero de 1974, se establece: "El Instituto de Difusión, Radio y Televisión de Misiones, es un ente autárquico que depende jerárquicamente del Titular del Poder Ejecutivo de la provincia. Es un organismo de Interés público tendiente a la información veraz, destinada a la mayor cantidad de difusión posibles, privados y oficiales; sirve a una comunidad solidaria al servicio del hombre misionero en igualdad de oportunidades".

Obsérvese que en el primer párrafo de este reglamento orgánico, ya se dispone que el IDIRATEMI sea un organismo que tiene que "estar al servicio de la comunidad". Por lo que en el segundo párrafo afirma: "Asimismo contribuye a lograr una provincia integrada, sin diferencias injustas, donde todos los habitantes pueden gozar de los mismos derechos y a los beneficios del progreso, y de la técnica. La preservación de los intereses provinciales y nacionales a través de la información contribuirá a lograr una estructura de seguridad apta para la paz y también en los momentos de conflictos, facilitando el ejercicio de la democracia eficiente y estable, bajo la forma de gobierno representativo del pueblo".

$\mathrm{Y}$ además, agrega:

"Los aspectos mencionados se apoyan en un principio fundamental, que es, el de respetar la dignidad del hombre, facilitando su realización como ser libre, logrando que prevalezca el interés provincial y nacional, por cuanto estos involucran los sentimientos y valores fundamentales de la comunidad argentina, así como el de asegurar a todos los habitantes de la Provincia el derecho a la libertad de información, en especial, en el Área de Frontera, 
donde en la actualidad su población se encuentra aislada; promover la difusión de la palabra y de la imagen al servicio de la verdad, la moral y el bien común, neutralizar las distorsiones que afecten a las estructuras de información".

Es que se está en 1974, Juan Domingo Perón (12/10/73 - 1/7/74) es el Presidente en la Argentina y un fuerte sentimiento nacionalista y popular circula por el país. Y esta impronta, no solo la vemos en la reglamentación, sino también en algunas modificaciones y en los criterios que se siguen; por ejemplo, para la composición del directorio, que son similares a los de la década de la '60, en donde no sólo están representados sectores de la educación y la cultura, sino también los trabajadores.

Este Instituto, el IDIRATEMI, sobrevivió a distintos acontecimientos políticos; entre ellos, la intervención federal a la provincia por parte de Juan Carlos Taparelli (21/1/1975 - 25/5/1975) quién convocó a elecciones que se realizaron en abril de ese año y donde resultó electo gobernador, el escribano Miguel Ángel Alterach (25/05/1975 - 24/03/1976).

El 1 de julio de 1974, falleció Juan D. Perón y, asumió la presidencia de la Argentina, su esposa María Estela Martínez (1/7/1974 - 24/3/1976), quién fue derrocada por un nuevo golpe militar, el más terrorífico que se recuerde en la historia argentina.

\section{CONSTRUYENDO ARGENTINIDAD}

En Misiones, se hizo cargo el Capitán de Navío René G. Buteler (24/4/1976 - 17/3/1977). Durante su gobierno, el 6 de noviembre de 1976, por Decreto 1350, se pone al aire la emisora LT 46 Radio Provincial Bernardo de Irigoyen, la localidad más oriental del país en la frontera con el Brasil, para reafirmar los derechos argentinos en esta parte del país y ser una barrera a la penetración de los medios brasileños (Garcia Da Rosa 2004). Y, en diciembre de 1976, se realizó un diagnóstico sobre "Redes de Comunicación y sus características", que se publicó en el "Atlas General de la Provincia de Misiones". En éste, se sostiene que la potencia de los medios misioneros es "escasa" comparada con la de los brasileños, "y dado que en su mayor parte son encaradas como empresas puramente comerciales antes que como servicio público, sufren un perpetuo estado de crisis económica" (Garcia Da Rosa, 2004:146 y 147). En una palabra, no son emisoras de servicio público porque no están relacionadas con los objetivos del Estado. 
El marzo de 1977, se hizo cargo del gobierno de la Provincia, Rodolfo R. Poletti (17/03/1977 - 01/11/1978). A este militar le correspondió la responsabilidad de eliminar el 25 de julio de 1977, por Ley No 821 del régimen, el IDIRATEMI; y crear, con ese mismo instrumento, el Ente Autárquico LT 85 Canal 12 de la ciudad de Posadas (Art. $2^{\circ}$ ); las emisoras LT 17 Radio Provincia de Misiones (que ya estaba en el aire) y LT 46 Radio Provincial Bernardo de Irigoyen (a instalarse) (Art. $3^{\circ}$ ).

Estos medios dependían de la Secretaría de Relaciones de Gobierno creada por Decreto $\mathrm{N}^{\circ} 1347$, en cuya estructura se encontraba la Dirección General de Información Pública a la que se le dio por misión "difundir la adecuada imagen del Gobierno de acuerdo a las pautas en vigencia, y dando a publicidad los propósitos, actos, acciones y planes de Gobierno", hecho que se cumplió al pie de la letra.

El 4 de enero de 1979 por decreto № 29, la Secretaría de Relaciones de Gobierno se transformó en Secretaría de Información Pública (Art. $4^{\circ}$ ), y de ella pasaron a depender todos los medios del Estado provincial; pero, la política comunicacional será la misma. Así los medios del estado dejarán nuevamente de ser "un servicio público" para convertirse en un "vocero del gobierno".

\section{LOS MEDIOS EN DEMOCRACIA}

Lo que importa a nuestro estudio, es que en 1983, la Argentina con Raúl Alfonsín (10/12/83 - 8/7/89) recuperó la democracia y en Misiones, Ricardo Barrios Arrechea (11/12/1983 - 17/09/1987) será el gobernador. Antes de entregar el gobierno, las Fuerzas Armadas publicaron en Misiones, en diciembre del 1983, un documento bajo el título "Provincia de Misiones - Acción de Gobierno - 1976/1983- Administrar con honestidad es la base de un buen gobierno". En él se realiza un informe de la gestión cumplida por el régimen a partir del 24 de marzo de 1976, durante "7 años y 9 meses de gobierno". De ese trabajo rescatamos un dato: "En los planes de radiodifusión, Misiones era considerada prioridad uno" ${ }^{33}$. Lo que se pretendió y no se logró, era instalar nuevos medios a lo largo de toda la frontera.

El 2 de octubre de 1984, Ricardo Barrios Arrechea, por Decretó № 3512 reestructuró la Secretaría de d Pública creada durante el régimen militar, y le

33 Esto se encuentra en el Capítulo VIII del citado informe que no registra número de páginas. 
asignó por misión "velar por el cumplimiento del principio republicano que hace a la información de la acción del Gobierno al pueblo de la provincia y mantener estrecho contacto con la comunidad, en relación a la divulgación de las inquietudes de la misma con respecto a sus gobernantes".

Pero, poco a poco, la política del gobierno comenzará a tener más presencia en el discurso y reducirá las prioridades de construcción de ámbitos de encuentros y reconocimientos a las necesidades electorales del partido en el gobierno.

A Barrios Arrechea le sucedió Julio César Humada (11/12/1987 - 11/12/1991). La política comunicacional no variará mucho en cuanto a lo que se venía aplicando. No obstante, el 30 de marzo de 1990, en la segunda mitad de su gobierno, en uno de los momentos más críticos por lo que económicamente estaba pasando el país (la hiperinflación) encontramos la presentación de "Las ideas del Poder Ejecutivo para impulsar el desarrollo de la provincia de Misiones - Bases para iniciar la consulta y la concertación económico social”; una propuesta de trabajo elaborado por el Gobierno a través de un Comité de Subsecretarios y Presidentes de entes descentralizados y el Consejo Federal de Inversiones. El objetivo era impulsar un debate amplio sobre temas que se consideraban centrales como la educación, la cultura, la salud, etc., en donde la sociedad civil a través de sus representaciones podían plantear "coincidencias, discutir las diferencias e incorporar sugerencias para concluir finalmente con un acuerdo económico y social", como base y punto de partida de un trabajo en conjunto que tenía por fin "construir el futuro de Misiones" (Gobierno de Misiones, 1990:1 y 2).

En el marco de una "Política de prestaciones sociales básicas" desarrolló el "Programa de Educación, Cultura y Comunicación Social”. En la página 64 , le dedicó tres párrafos a los medios, en donde propone como alcanzar estos objetivos:

"El Proyecto Comunicacional habrá de contribuir desde su propio escenario a la consolidación de las propuestas programáticas culturales y educativas para completar la formación integral y permanente del hombre. Para ello se formulará, debatirá y adoptará una Política Comunicacional que bajo la forma de un Programa Integral de Comunicación Social, orientará el uso de los medios de comunicación social para la satisfacción de las demandas que se generen, e integrará a todos los operadores culturales y educativos al sistema como protagonistas del mismo, apoyando en contenidos capaces de promover el rescate de nuestros valores y nuestra identidad nacional-re- 
gional" (Gobierno de Misiones, 1990:64).

Pero, más allá de esas intenciones, si bien los medios del estado y en particular, Canal 12 fue uno de los vocero oficiales del gobierno durante el régimen militar, durante el proceso de transición institucional ello no variará significativamente hasta la creación, por decreto 1462 del 22 de julio 1993, del MULTIMEDIOS SOCIEDAD ANONIMA CON PARTICIPACION ESTATAL MAYORITARIA (Multimedios SAPEM).

El objetivo que motivó esa decisión política fue: "la racionalización del Estado Provincial”. La fundamentación: "Que LT 85 TV Canal 12 ha venido operando en un mercado fuertemente regulado, manteniendo actualmente una estructura interna, administrativa y jurídica que no contempla su competitividad, generando déficit de envergadura y por ende resultando un negocio no rentable para el Estado; económica y financieramente inconveniente"; Qué a los efectos de revertir la realidad deficitaria y antieconómica y revalorizar las emisoras para devolverle una imagen que despierte interés comercial con miras y como paso previo a una futura privatización, es necesario valerse de una figura ágil que brinda una sociedad comercial..." 34.

El 29 de septiembre de 2011, dio otro paso trascendente. A partir de un proyecto (que por unanimidad se convertirá en Ley) presentado por los diputados Carlos Rovira, Hugo Passalacqua y Salvador Cabral Arrechea, no solo se creará el Multimedios Digital en el ámbito de Multimedios Sociedad Anónima con Participación Estatal Mayoritaria, sino que adherirá la Provincia de Misiones a la Ley Nacional № 26.522, de Servicios de Comunicación Audiovisual. En los fundamentos, se considera que la comunicación audiovisual, como actividad social de interés público y de carácter esencial para el desarrollo sociocultural de la población, requiere un cambio en su visión y manejo. En principio, no solo es una herramienta pensada para la democratización de la comunicación sino también para la integración regional, unos de los objetivos centrales de la ley de medios.

\section{REFLEXIONES FINALES}

Acordamos, en principio, que en la historia de Misiones se puede marcar cuatro periodos (Garcia Da Rosa 2005) en donde la gráfica, la radio y luego la televisión fueron utilizados ( $y$ en algunos casos) pensados para cumplir con 
determinadas finalidades.

1. En los orígenes (1872-1927), fue la construcción de civilidad y luego ciudadanía. Había que transformar esa aldea marginal, situada en los bordes del país, para mostrar su desarrollo y potencial ante la centralidad. La prensa gráfica desempeñará ese rol y será el medio por el cual distintos sectores ligado a la cultura, la economía y/o la política la utilizarán para hacer visibles realidades diversas y diferentes de una zona multicultural que comenzó a buscar una identidad propia que lo distinguiera de lo nacional pero a su vez que lo uniera a la historia del país.

2. Con la aparición de la radio (1927), este proceso se profundizará. En una primera instancia, es herramienta para hacer masiva la difusión de esta idea de misioneridad, cuyos principales destinatarios son quienes ejercen el poder en la centralidad. Las disposiciones iniciales que se tomaron para encuadrar el funcionamiento de este nuevo medio no tuvo en cuenta su existencia ni la importancia que tenía para una provincia como la Misiones. Por eso tuvo que trasladarse al Paraguay. Es tiempo en donde la frontera no es pensada desde lo político sino más bien desde el reconocimiento de una historia común, experiencias compartidas y de relaciones familiares muy fuertes de uno y otro lado del río, que la tornaron flexible. En este tiempo, sobre todo la gráfica será un actor político, que jugará un rol muy fuerte en la campaña para lograr la provincialización de lo que hasta ese momento era Territorio Nacional. Es el momento, que la grandes cadenas de radio en la Argentina dejaron su impronta instalando filiales (1941/42) a uno y otro lado del río. Fueron emisoras desde las cuales no solo se buscó crear mercados pensados desde el logro de la rentabilidad económica, sino fueron instrumentos -en determinados momentos y contextos- para instalar una idea de Nación y argentinidad.

3. En esta búsqueda de construcción de "lo argentino", y sobre todo, en el marco de regímenes militares, se tomarán decisiones para instalar medios que sean propiedad del estado provincial, pensados como una herramienta más para resguardar la frontera pero también para homogeneizar la diversidad cultural de la sociedad misionera. A estos medios del Estado, radios (1964 y 1977) y televisión (1972), se les asignarán distintas funciones de acuerdo con quién esté rigiendo los destinos de la provincia. Durante los 
regímenes militares será para controlar y argentinizar. En democracia, son concebidos como medios públicos, pluralistas y al servicio de la comunidad. Las normas que se dictaron para alcanzar estos objetivos, solo se cumplieron en el primer caso. En el segundo, es una deuda pendiente.

Lo significativo, es que en todas estas normas que se dictaron desde la aparición de la radio, se ve en la provincia una fuerte confrontación entre una idea de Nación y Provincia, en donde los medios fueron usados para la imposición de determinados proyectos, que aún hoy están en debate y no sin tensión, en permanente disputa por la identidad y autonomía 


\section{REFERÊNCIAS}

GARCIA DA ROSA, Carlos y ALVAREZ, Norma (2012): "La evolución del periodismo gráfico en la historia de Misiones (1881-1953)", en: Del prudente saber y el máximo posible de sabor, $\mathrm{N}^{\circ} 7$, Facultad de Ciencias de la Educación, UNER.

GARCIA DA ROSA, Carlos (2002): "Aportes para la construcción de un mapa mediático de Misiones", en: Estudios Regionales. Revista de la Secretaría de Investigación y Posgrado Facultad de Humanidades y Ciencias Sociales. Universidad Nacional de Misiones), Año 10, $\mathrm{N}^{\circ} 21$.

(2004): Estamos con vos. Canal 12 un medio de la comunidad. (Tesis Maestría en Periodismo y Medios de Comunicación). Inédita. UNLP.

(2006) “Aproximación a una historia de los medios en Posadas: una primer lectura”, en: Estudios Regionales. Revista de la Secretaría de Investigación y Posgrado Facultad de Humanidades y Ciencias Sociales. Universidad Nacional de Misiones), Año $14, \mathrm{~N}^{\circ} 32$.

WILLIAMS, Raymond (1992): Historia de la comunicación - de la imprenta a nuestros días, Vol. 2, Bosch Casa Editorial, Barcelona.

ULANOVSKY, Carlos; MERKIN, Marta; PANNO, Juan; TIJMAN, Gabriela (1997): Días de Radio - Historia de la Radio Argentina, Espasa Calpe, $5^{\circ}$ edición, Buenos Aires.

PEREZ, Verónica Paola de Schapovaloff (2005): "Una familia de origen francés a la vanguardia de la tecnología y sistemas de comunicación masiva: los Cormillot”, en: IV Jornadas sobre Poblamiento, Colonización e Inmigración en Misiones, Edición Instituto Antonio Ruiz de Montoya, Posadas, Misiones.

CABRAL, Salvador; CAMBAS, Graciela; AMABLE, Hugo W.; ZAMBONI, Olga; ALARCON, Raquel (1990): Misiones una provincia en el corazón de América, Ediciones Corregidor, Buenos Aires.

BARTOLOME, Leopoldo (2000): Los colonos de Apóstoles - Estrategias adaptativas y etnicidad en una colonia eslava de Misiones, Editorial Universitaria de Misiones.

BAYARDO, Rubens y LACARRIEU, Mónica (compiladores), (1998): Globalización e identificación Cultural, Ediciones Ciccus, Buenos Aires.

Documentos

"Area de Frontera Bernardo de Irigoyen - Diagnosis Socio-Económica"- Gobierno de Misiones - Secretaria de Planificación y Control - Posadas - 1976.-

“Atlas General de la Provincia de Misiones" - Provincia de Misiones - Secretaría de Planificación y Control - Dirección General de Estadísticas y Censos - Diciembre de 1976.-

"Las ideas del gobierno para impulsar el desarrollo de la provincia de Misiones - Bases para iniciar la consulta y la concertación económico social” - Gobierno de la Provincia de Misiones - Posadas - Marzo de 1990.-

"Plan Misiones 1980-2000" - Tomo 3 - "El espacio adaptado" - Gobierno de Misiones Posadas -8 de junio de 1980.- 
“Provincia de Misiones - Acción de Gobierno 1976-1983” - Diciembre de 1983.-

CAMBAS, Graciela - "Orígenes del periodismo en Misiones" - Publicado en Suplemento Especial del diario El Territorio, en adhesión a su 70 aniversario - Junio de 1995-

Ley Provincial Nº111, del 14 de septiembre de 1961.

Ley Provincial N²27, del 7 de octubre de 1964.

Ley Provincial № 280, del 2 de julio de 1965.

Decretos Nacionales Nº 5067 y 5068, del 8 de septiembre de 1969.

Ley Provincial № 405, diciembre de 1973.

Decreto Provincial №355, del 20 de febrero de 1974.

Decreto Provincial $\mathrm{N}^{\circ} 1350$, del 6 de noviembre de 1976.

Ley Provincial No 821, del 25 de julio de 1977.

Decreto Provincial № 29, del 4 de enero de 1979.

Decreto Provincial No3512, del 2 de octubre de 1984.

Decreto Provincial № 1462, del 22 de julio 1993.

RECEBIDO EM: 16/05/2015

APROVADO PARA PUBLICAÇÃO: 02/07/2015 


\section{Carlos Alberto García Da Rosa}

Licenciado en Periodismo y Magister en Periodismo y Medios de Comunicación. Docente e investigador de la Carrera de Comunicación Social, Facultad de Humanidades y Ciencias Sociales de la Universidad Nacional de Misiones. (UNaM)

\section{Norma G. Alvarez}

Profesora y Licenciada en Historia, Facultad de Humanidades y Ciencias Sociales, UNaM. Magister Artis en Historia, Facultad de Humanidades, Universidad Nacional de Mar del Plata. Profesora Adjunta Regular de Procesos Sociohistóricos: modernos y contemporáneos, Carrera de Comunicación Social; Historia Universal III, Carrera de Historia. UNaM. 
